\title{
Clinical and electrophysiological follow-up of modafinil treatment for multiple sclerosis patients with fatigue symp-
} tom

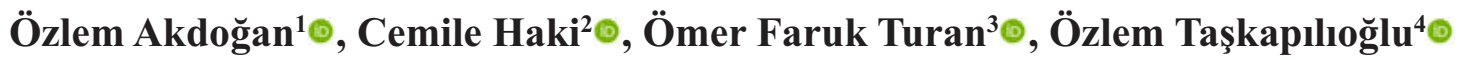 \\ ${ }^{1}$ Department of Neurology, University of Health Sciences, Istanbul Training and Research Hospital, Istanbul, Turkey \\ ${ }^{2}$ Department of Neurology, University of Health Sciences, Bursa Yüksek Ihtisas Training and Research Hospital, Bursa, Turkey \\ ${ }^{3}$ Department of Neurology, Uludağ University School of Medicine, Bursa, Turkey \\ ${ }^{4}$ Department of Neurology, Acıbadem University School of Medicine, Istanbul, Turkey
}

\begin{abstract}
Objectives: In our study, we investigated the effects of modafinil therapy on clinical and neurophysiological tests of multiple sclerosis (MS) patients with fatigue.

Methods: The study was performed on 18 MS patients (16 females, 2 males) at Uludağ University School of Medicine, Department of Neurology, who are followed up according to Mc Donald's criteria, who had 36 points or above based on the fatigue assesment scala (FAS), whose Beck depression inventory points were 16 and below, whose thyroid, liver and renal functions were evaluated as normal, and who had no systemic disorder. All patients had neurological examination and their expanded disability status scale (EDSS), fatigue impact scala (FIS) and multiple sclerosis quality of life (MSQoL-54) were evaluated. Somatosensory evoked potential (SEP), visual evoked potential (VEP), brainstem auditory evoked potential (BAEP), visual event related evoked potential (visual P300) were performed in our neurophysiology laboratory. After that the patients were given modafinil $100 \mathrm{mgr} 1 \mathrm{x} 1$ (morning) for 1 week, the following weeks $2 \times 1$ (morning and noon). At the end of the 6 weeks of therapy the patients were called to the neurology polyclinic, and their neurological examinations, EDSS, FIS, MSQoL-54, SEP, VEP, BAEP and visual P300 were repeated.
\end{abstract}

Results: When the patients' previous and subsequent FIS and MSQoL-54 total scores were compared, a significant statistical difference was found. When all 3 subgroups of FIS (consciousness, physical and social) were evaluated after the modafinil therapy, a significant statistical decrease in previous and successive scores were found. It is found out that modafinil therapy improves life quality which is evaluated due to MSQoL-54 $(p<0.05)$. A significant statistical relation between the number of MS disease attacks and the three subgroups of MFIS was not figured out $(p>0.05)$. There were no statistically significant relation between the FAS, EDSS and Beck depression inventory scores before the modafinil therapy had been applied $(p>0.05)$. There was a statistically correlation between Beck depression inventory score and FIS's social subgroup $(p=0.017)$. When the patient's SEP, VEP, BAEP, visual P300 average test values before and after the modafinil therapy were compared, a statistically significant difference was not observed. Conclusions: In our study, it is found that modafinil therapy, which is used against fatigue, one of the MS disase's most common symptom, has a positive impact on MS life quality and patients' clinical symptoms of fatigue, although it has no effect on patients' evoked potential methods (BAEP, SEP, VEP, visual P300) performed in neurophysiology laboratory.

Keywords: multiple sclerosis, fatigue, modafinil, evoked potential, fatigue severity scala

How to cite this article: Akdoğan Ö, Haki C, Turan ÖF, Taşkapılıoğlu Ö. Clinical and electrophysiological follow-up of modafinil treatment for multiple sclerosis patients with fatigue symptom. Eur Res J 2020;6(4):326-336. DOI: 10.18621/eurj.493073

Address for correspondence: Cemile Haki, MD., University of Health Sciences, Bursa Yüksek Ihtisas Training and Research Hospital, Department of Neurology, Mimar Sinan Mahallesi,Emniyet Cd., No: 35, 16310 Ylldırım, Bursa, Turkey, E-mail: cemilehaki@gmail.com, Tel:+90 2242944000 
A lthough multiple sclerosis (MS) is a clinically heterogeneous neurological disease, it is difficult to diagnose the disease due to the diversity of its symptoms, its fluctuating nature, and its heterogeneity [1]. Despite its disadvantages in the evaluation of cognitive deterioration and upper extremity functions as demonstrated in clinical MS studies, the expanded disability status scale (EDSS) is used as the primary measurement method of disability in MS [2].

Fatigue is today recognized as the most prevalent symptom of MS. MS-derived fatigue is different from the usual fatigue that follows strenuous activities, and it is believed that such fatigue is specific to MS. Freal et al. [3], who were the first to study fatigue complaints of MS patients, reported that $75-90 \%$ of the patients included in their sample complained about fatigue.

The symptoms and consequences associated with fatigue include physical fatigue, mental fatigue, $a b$ sence of motivation, concentration difficulty, incapability of fulfilling tasks, sense of depression, sense of anxiety, tiredness after sleep, general and specific muscle weakness, diminished performance at home and/or at work, pain and/or physical ailments, and sleep disorders [4].

This study aims to investigate the qualitative effect of modafinil treatment on fatigue assessment scales and on the quality of life scale, and the quantitative effect of the said treatment on the measurement of evoked potentials and on clinical and neurophysiological tests. To the best of the researchers' knowledge, this is the first study to analyze the effect of modafinil treatment administered for MS-related fatigue, on somatosensory evoked potential (SEP), visual evoked potential (VEP), brainstem auditory evoked potential (BAEP), and all of the event-related endogenous potentials.

\section{METHODS}

A total of 18 patients (16 females and 2 males), who had received follow-up care for 6 months at Uludağ University School of Medicine, Department of Neurology due to MS diagnosis, were included in the study after they had given their informed written consent to participate. The study was approved by the local ethics committee. To be included in the study, patients had to have no systemic disease, no pathology according to thyroid function tests, liver function tests, and kidney function tests, and they had to have complaints about fatigue and scores of $\geq 36$ and $\leq 16$ on the fatigue assessment scale (FAS) and Beck's Depression Inventory, respectively. Patients who had started to undergo antidepressant treatment within the last 3 months and/or who had had a seizure within the last 4 months were excluded from the study.

The results from the EDSS, the fatigue impact scale (FIS), and the MS Quality of Life Scale-54 (MSQoL-54) of the patients included in the study were evaluated as part of the neurological examination. The modafinil treatment of the patients started with the administration of a $100 \mathrm{mg}$ dose of $1 \times 1$ tablet (morning) in the first week and a $100 \mathrm{mg}$ dose of $2 \mathrm{x} 1$ tablet (morning and noon) in the weeks that followed. Prior to the modafinil treatment, SEP, VEP, BAEP and visual event-related endogenous potential (Visual P300) were applied on the patients in the neurophysiology laboratory. At the end of week 6 of the treatment, the patients visited the outpatient department and underwent a neurological examination again based on the assessment of EDSS, FIS, MSQoL54, SEP, VEP, BAEP, and Visual P300.

\section{Disability Assessment}

The participants' level of neurological impairment was assessed using the Kurtzke EDSS. Impairment in 8 functional systems is measured with this scale, with most of the scores in the functional system being assessed in a range from 0 to 6 , where 0 showing normal neurological examination, whereas 10 indicates MS-related death [2].

\section{Fatigue Assessment Scale (FAS)}

Fatigue symptoms were scaled with FAS, which is a nine-part scale used to evaluate the overall effect of fatigue on daily activities. Each part is scored according to a seven-point Likert-type scale, where 1 is never agree and 7 is completely agree. The FAS score is calculated by summing up or averaging out the scores of the nine parts. FAS is effective for distinguishing patients with fatigue complaint who need treatment and those who do not require treatment. Moreover, it is used to detect the effects of the treatment administered to patients with fatigue symptoms [5]. 
Fatigue Impact Scala (FIS)

The FSS, which evaluates physical, psychological, and cognitive functions, is more detailed than FAS. There are 10 items under the cognitive component, 10 items under the physical component and 20 items under the psychosocial component. Responses to each item range from 0-3 (0: no problem, 3: very big problem) [6].

\section{Quality of Life Scale (MSQoL-54)}

For this scale, 18 MS-related questions were added to the original 36-Item Short Form Health Survey Questionnaire (SF-36), which was developed from the Medical Outcome Study and is used for all chronic diseases (10). SF-36 includes 36 items under 8 scales. Of these 36 items, 10 are related to physical function, 4 to the role of physical function, 2 to body pain, 5 to general health, 4 to liveliness, 2 to social function, 3 to the role of emotional function, and 5 to mental health. Vicrey et al. [7] added 18 items to this scale, of which 4 are related to health-related stress, 4 to sexual function, 1 to satisfaction in sexual function, 2 to quality of life, 4 to cognitive function, 1 to energy, 1 to pain, and 1 to social function.

\section{Electrophysiological Procedures}

The patients' SEP, VEP, BAEP, and P300 were recorded at room temperature $\left(22^{\circ} \mathrm{C}\right)$ in the Uludag University Schol of Medicine, Neurophysiology Laboratory. A Medelec/TECA "Sapphire" brand device was used to conduct these measurements after performing a complete skin cleansing process. Electrode impedances were kept below $5 \mathrm{kOhm}$ in all of the applications.

The waves that emerged in the first $10 \mathrm{~ms}$ were recorded with BAEP following an 80-85 dB monoaural click stimulus. The click was applied 60 decibels above the threshold of hearing to one, while the other ear was masked by noise. Active electrode and reference electrode were placed on point $\mathrm{CZ}$ and ipsilateral mastoid (M1 and M2), respectively, during recording. Analysis duration was set as $100 \mathrm{~ms}$, with the polarity alternans and frequency limits placed at 100-200 Hz.

Recording was performed on the occipital by stimulating the eyes with VEP through a checkerboard-pattern reversible stimulus. The color of the black-white checkerboard-pattern squares on the screen changed every $20 \mathrm{~ms}$. The patients were seated $90 \mathrm{~cm}$ from a TV screen, whereon the stimuli, activated 3 cycles per second, were watched. Superficial electrodes were used for recording. Active electrode and reference electrode were put on point $\mathrm{OZ}$ and point FZ, respectively. Frequency limits were set to $1-100 \mathrm{~Hz}$, while the analysis duration was set as $250 \mathrm{~ms}$. The middle part of the screen was marked to ensure visual fixation. The whole screen was able to be seen at a $23^{\circ}$ angle, while a square on the screen was able to be seen at a $1^{\circ}$ angle. As one eye was stimulated, the other eye was closed with an eye patch. Median SEP (mSEP) was obtained through electrical stimulation of the right and left median nerve. The electrical stimulation was applied at a frequency of three $50 \mathrm{~ms}$ per second using a sensitivity just over the motor threshold. The records were attained from the $\mathrm{C} 3$ contralateral cortex region.

Tibial SEP (tSEP) was obtained with the electrical stimulation of $\mathrm{n}$. tibialis posterior from ankle. Successive electrical stimulation was applied at a frequency of four $100 \mathrm{~ms}$ per second using a sensitivity just over the motor threshold. Recordings were performed in the foot region $(\mathrm{Cz})$. Frequency limits were set as $10-2000 \mathrm{~Hz}$, while the analysis duration was set as $100 \mathrm{~ms}$.

Event-related endogenous potentials are a type of evoked potential that forms as a response to an event outside or a stimulus. It occurs when a person distinguishes two stimuli of different qualities whose recurrence intervals are variable (target and nontarget) when he/she pays attention to the stimuli. P300, which was used to assess the mental functions, is the most well-known wave with respect to event-related endogenous potentials [8]. During P300 assessment, the target stimulus was sent to both eyes at various intervals following the routine stimulation repeated once a second. Active recording was performed based on point $\mathrm{Pz}$. The duration of routine stimulations and target stimulations were $2 \mathrm{~ms}$ and $30 \mathrm{~ms}$, respectively. Routine stimulations constituted $85 \%$ of all stimulations, while target stimulations constituted $15 \%$ of all stimulations. The average analysis duration was $1 \mathrm{~s}$, and the lower and upper frequencies were applied within a range of 0.1-50 Hz.

\section{Depression Assessment}

The patients were assessed with Beck's 
Table 1. Demographic and MS-related information

\begin{tabular}{lc}
\hline Number of patients $(\mathrm{n})$ & 18 \\
\hline Female/male, $\mathrm{n}(\%)$ & $16(88.9) / 2(11.1)$ \\
Mean age (mean \pm SD) (years) & $40.5 \pm 10.4$ \\
Mean age of onset of disease (mean \pm SD) (years) & $32.3 \pm 8.4$ \\
Clinical type of MS, $\mathrm{n}(\%)$ & $15(83.3)$ \\
$\quad$ Relapsing remitting & $2(11)$ \\
$\quad$ Secondary progressive & $1(5.6)$ \\
$\quad$ Rrelapsing progressive & $8.1 \pm 5.9$ \\
Mean duration of disease (mean \pm SD) (years) & $1.8 \pm 1.1$ \\
\hline Mean EDSS score (mean \pm SD)
\end{tabular}

MS = multiple sclerosis, EDSS = expanded disability status scale, $\mathrm{SD}=$ standard deviation

Depression Inventory to ascertain their depressive symptoms. Beck's Depression Inventory consists of 21 items, with each item having four response options. Every item is scored from 1 to 4 , and scores $\geq 17$ are evaluated as indication of depression [9]. The patients who received scores of $\geq 17$ were excluded from the study .

\section{Statistical Analysis}

Statistical assessment of the study data was performed with SPSS programme for Windows. A post hoc power analysis was conducted using a medium effect size, based upon findings of the present study. A medium effect size was obtained by comparing mean Physical dimension scores which were calculated from before treatment $(14.1 \pm 4.6)$ and after treatment $(8.5 \pm 6.3)$ terms for 18 participants. Using this effect size $(\mathrm{d}=0.75)$ with a sample size of 18 participants, achieved power was estimated as $81 \%$ at the significance level of $\alpha=0.05$. The median (minimum-maximum) was calculated for all data in cases where the mean standard deviation (mean \pm SD) was needed. Paired t-test and Wilcoxon signed-rank test were used to compare the pre-treatment and posttreatment scale scores. Correlation analyses were conducted for the correlations between the scale scores and Pearson or Spearman correlation coefficients were reported. A significance level of $p<0.05$ was set for all statistical analyses.

\section{RESULTS}

The mean age of the patients was $40.5 \pm 10.4$ years (males: 317 years; females $41.6 \pm 10.3$ years). The mean age of onset of MS symptoms was $32.3 \pm$ 8.4 years, while the mean duration of disease was 8.1 5.9 years. In terms of the clinical type of MS, 15

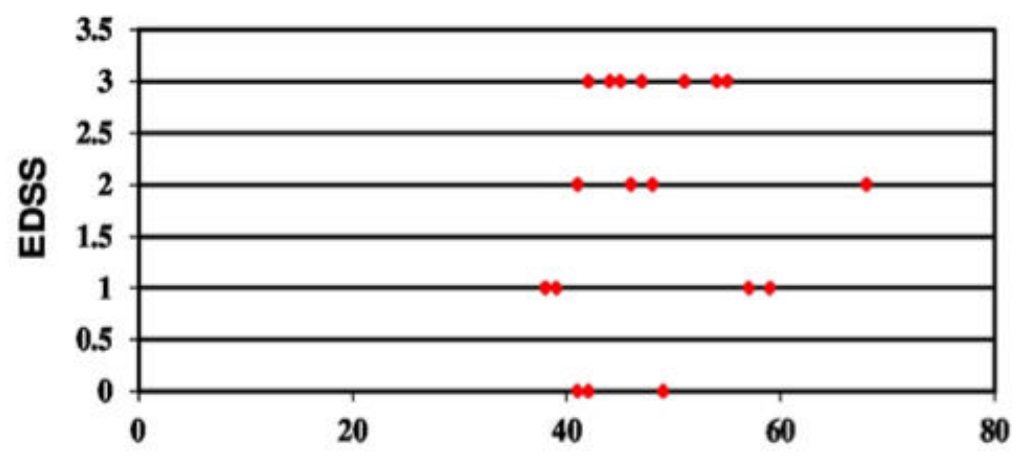

Fatigue Assessment Scale Score

Fig. 1. Relationship between the expanded disability status scores and fatigue assessment scores of the patients. 


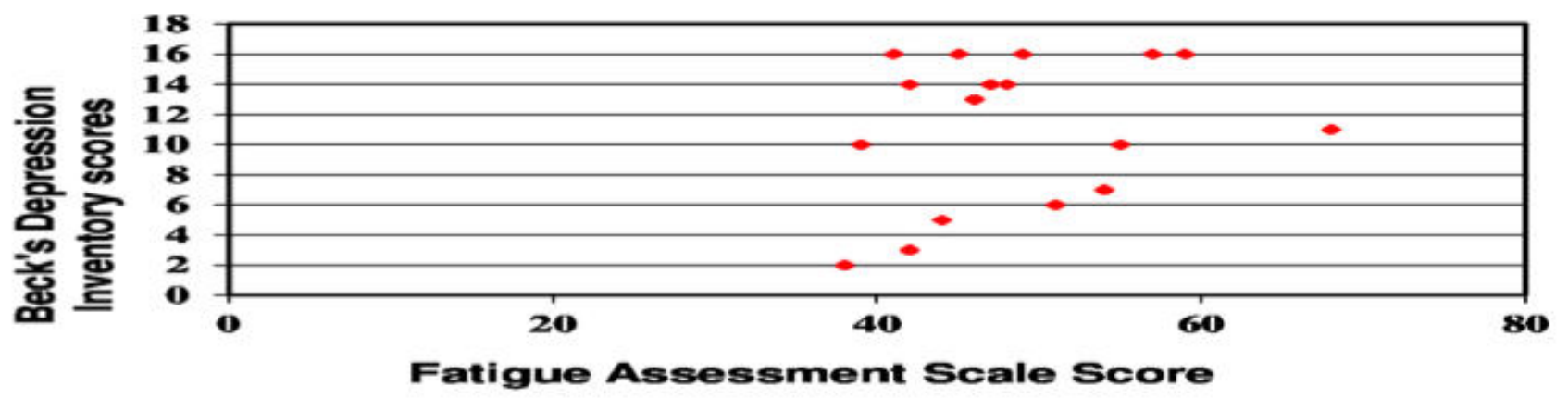

Fig. 2. Relationship between the scores on Beck's Depression Inventory and Fatigue Assessment Scale.

patients had relapsing remitting, 2 patients had secondary progressive, and 1 patient had relapsing progressive. The mean EDSS of the patients was 1.8 \pm 1.1 (Table 1).

Among the patients included in the study, 15 $(83.3 \%)$ were using an immunomodulator, while 3 (16.7\%) were not; of the 15 patients who were using an immunomodulator, 5 (27.8\%) had been on it for one year, $5(27.8 \%)$ for two years, $2(11.1 \%)$ for three years, $2(11.1 \%)$ for four years, and 1 (5.6\%) for five years. Seven patients were using beta interferon $1 \mathrm{~b}$ 0.3 MG (9.6 MIU) subcutaneous every other day, 3 patients were using beta interferon $1 \mathrm{a} 44 \mathrm{mcg}$ (12 MIU) subcutaneous three times a week, 4 patients were using glatiramer acetate $20 \mathrm{mg}$ subcutaneous every day, and 1 was using interferon beta 1 a $30 \mathrm{mcg}$ (6 MIU) intramuscular once a week.

Nine patients had been on antidepressants for at least for three years, while nine patients had not been taking antidepressants. Regarding MS onset symptoms, 4 patients had optic neuritis, 8 patients had pyramidal signs, 2 patients had cerebellar signs, 2 patients had cerebellar and pyramidal signs, and 2 patients had sensual signs. Regarding relapses, 2 patients had one, 6 patients had two, 4 patients had three, 3 patients had four, 1 patient had five and 2 patients had 6 . Within the last two years, 6 of the patients did not have any relapse, while 10 patients and 2 patients had one and two relapses, respectively.

There was a negative correlation between age and the pre-treatment score on the Beck's Depression Inventory (Spearman correlation coefficient $=-0.716$, $p=0.001$ ). No statistically significant relationship was found between the pre-treatment scores on the FAS and the EDSS (Spearman correlation coefficient $=$ $0.210, p>0.05$ ). (Fig. 1). No statistically significant relationship was found between the pre-treatment scores on the FAS and the Beck's Depression Inventory (Spearman correlation coefficient $=0.369$, $p>0.05$ ) (Fig. 2).

According to the Wilcoxon rank-sum test, the difference between the pre-treatment scores and posttreatment scores on Beck's Depression Inventory was statistically significant, with the Beck's Depression Inventory scores of the patients being significantly lower after the treatment. $(p<0.001)$ (Table 2). The mean total FAS score of all 18 patients after the treatment $(32.7 \pm 9.2)$ was statistically significantly lower than that before the treatment $(48.1 \pm 7.9)$. The difference between the total FAS scores was found to

Table 2. Beck's Depression Inventory scores

\begin{tabular}{cccc}
\hline & $\begin{array}{c}\text { Before modafinil } \\
\text { treatment }\end{array}$ & $\begin{array}{c}\text { After modafinil } \\
\text { treatment }\end{array}$ & $p$ value \\
\hline Beck's Depression Inventory Score & & & $<\mathbf{0 . 0 1 *}$ \\
Mean \pm SD & $10.7 \pm 5.0$ & $4.7 \pm 4.43$ & 4 \\
Median & 12 & $0-12$ \\
\hline Minimum-maximum & $2-16$ & \\
\hline
\end{tabular}

*According to Wilcoxon rank-sum test, $\mathrm{SD}=$ standard deviation 
Table 3. Relationship between the sub-dimensions of fatigue impact scale before the treatment and after the treatment

\begin{tabular}{|cccc}
\hline & Before the treatment & After the treatment & $\boldsymbol{p}$ value \\
\hline Cognitive dimension & & & \\
Mean \pm SD & $12.8 \pm 4.4$ & $8.8 \pm 7.5$ & $\mathbf{0 . 0 1 4 *}$ \\
Median & 12.5 & 11 & \\
Minimum-maximum & $6-20$ & $0-20$ & \\
Physical dimension & & & $\mathbf{0 . 0 0 7 *}$ \\
Mean \pm SD & $14.1 \pm 4.6$ & $8.5 \pm 6.3$ & \\
Median & 14 & 8.5 & \\
Minimum-maximum & $5-21$ & $0-21$ & $\mathbf{0 . 0 0 1 *}$ \\
\hline Social dimension & & & \\
\hline Mean \pm SD & $30.1 \pm 12$ & $16.8 \pm 12.5$ & 18.5 \\
\hline Median & 28.5 & $0-38$ & \\
\hline Minimum-maximum & $13-55$ & & \\
\hline
\end{tabular}

*Wilcoxon rank-sum test, $\mathrm{SD}=$ standard deviation

be statistically significant to the highest degree (Matched-pair t-test, $p<0.001$ ).

No statistically significant correlation between age and FAS values was detected (Pearson correlation coefficient $=0.153, p>0.05$ ).

Significantly lower values in the cognitive, physical, and social dimensions of FIS were determined during the post-treatment measurement based on the Wilcoxon rank-sum test. There were significant $(+)$ correlations between cognitive, physical, and social dimensions to the highest degree following the treatment (after the treatment, Spearman coefficients for the relationship between cognitive and physical dimensions $=0.744(p<0.001)$, for relationship between cognitive and social dimensions $=0.685(p=0.002)$ and for relationship between physical and social dimensions $=0.814(p<0.001))$. No statistically significant relationship was found

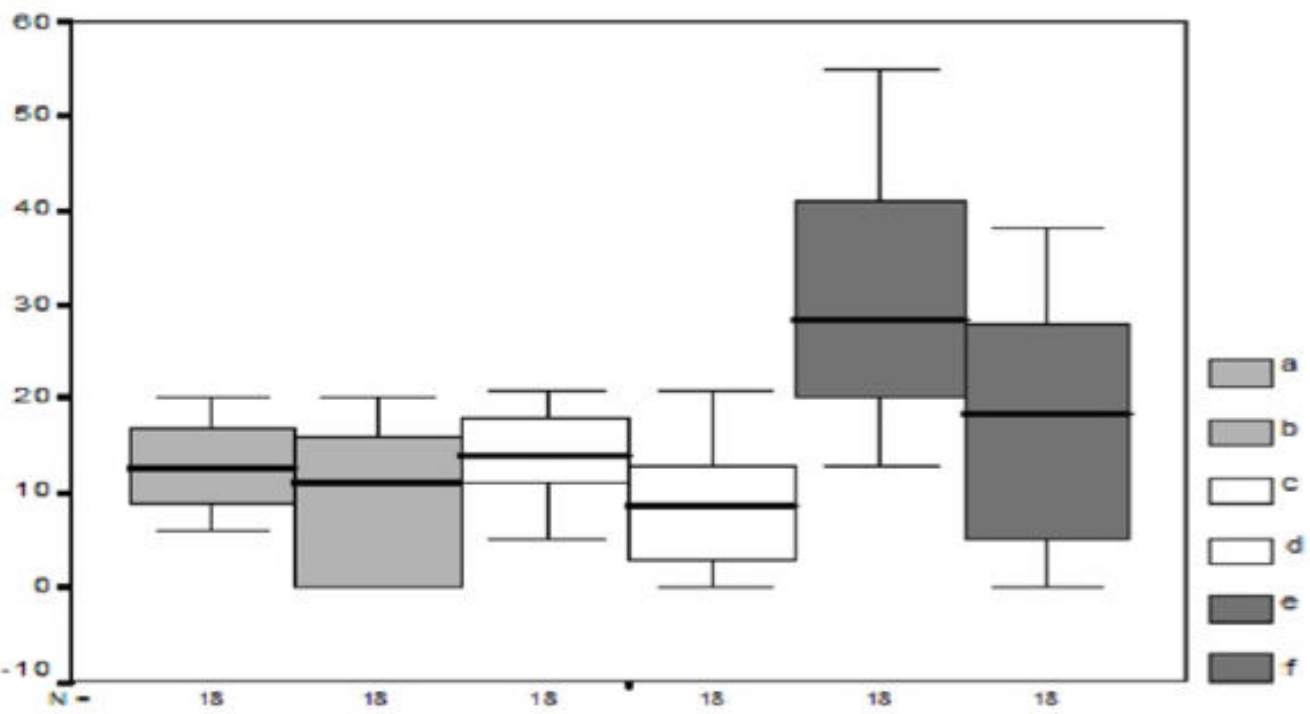

Fig. 3. The relationship between sub-dimensions of the Fatigue Impact Scale. (a) pre-treatment cognitive dimension, (b) post-treatment cognitive dimension, (c) pre-treatment physical dimension, (d) post-treatment physical dimension, (e) pretreatment social dimension, (f) post-treatment social dimension. 
Table 4. Relationship between the sub-dimensions of MS Quality of Life Scale (MSQoL54) before the treatment and after the treatment

\begin{tabular}{lcccc}
\hline $\begin{array}{l}\text { MS Quality of } \\
\text { (MSQoL-54) }\end{array}$ & Scale & Before the treatment & After the treatment & $\boldsymbol{p}$ value \\
\hline Physical health & $52.30 \pm 13.01$ & $72.23 \pm 13.06$ & $<\mathbf{0 . 0 0 1}$ \\
Cognitive health & $54.25 \pm 19.33$ & $69.79 \pm 16.39$ & $\mathbf{0 . 0 0 1}$ \\
Change in health & $58.33 \pm 25.72$ & $73.61 \pm 18.13$ & $\mathbf{0 . 0 0 5}$ \\
Sexual function & $54.16 \pm 21.43$ & $68.05 \pm 23.95$ & $\mathbf{0 . 0 0 8}$ \\
\hline
\end{tabular}

between the number of MS relapses and the 3 between pre-treatment values and post-treatment dimensions on the FIS $(p>0.05)$ (Table 3) (Fig. 3). values on the four sub-dimensions of the MSQoL-54. There was a statistically significant moderate According to the matched-pair t-test, pre-treatment correlation between the score on the Beck's values on physical health and cognitive health were Depression Inventory and the social dimension of the significantly lower than their respective post-treatment FIS (Spearman correlation coefficient $0.553, p=$ values ( $\mathrm{p}$ values based on matched-pair t-test: physical 0.017). health; $p<0.001$, cognitive health; $p=0.001$ ). When

A statistically significant difference was found pre-treatment values and post-treatment values related
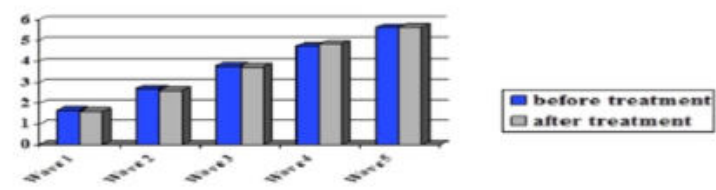

Figure 4a: Left BEAP
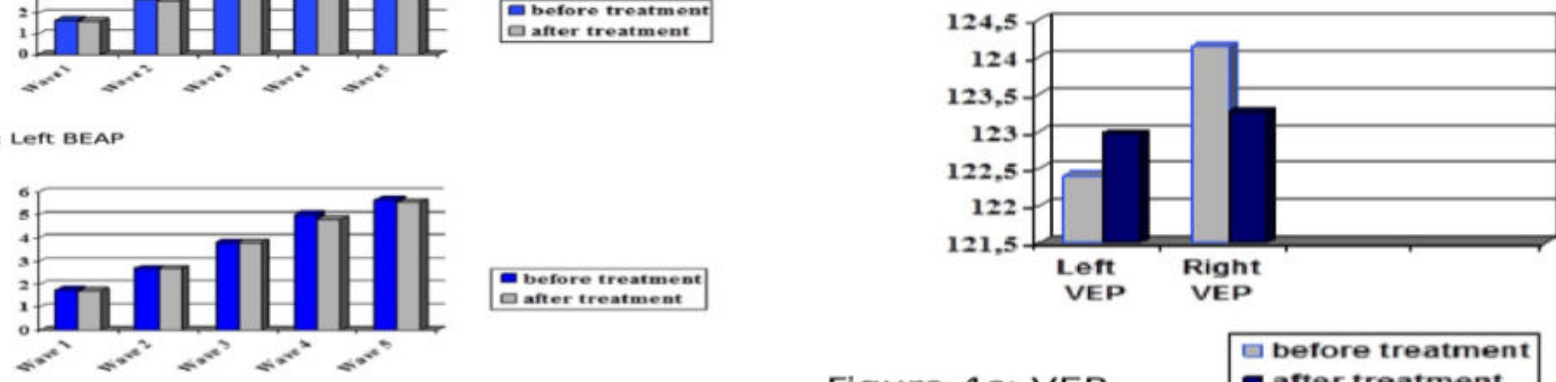

Figure 4C: VEP

$\square$ before treatment - after treatment

Figure 4b: Right BEAP
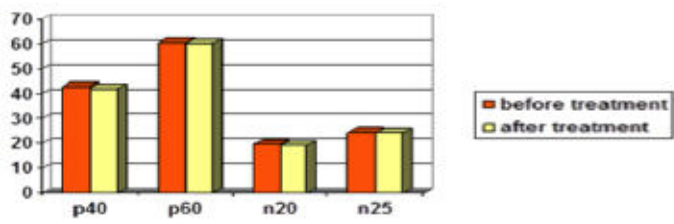
after treatment
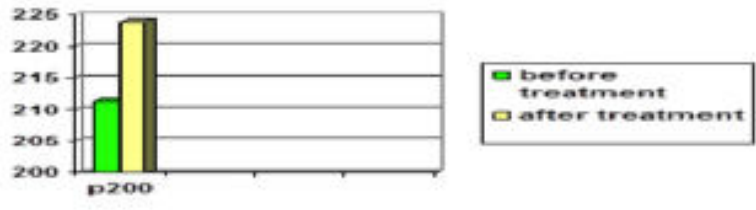

Figure 4d:Left SEP
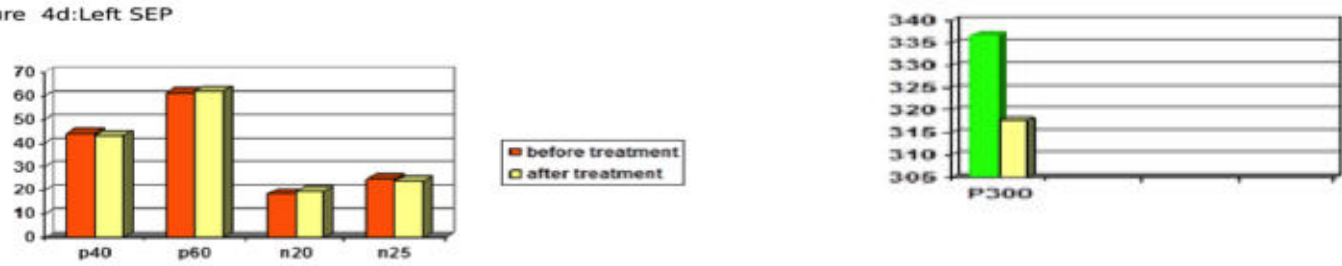

Figure 4f,g: p200.p300

Figure 4e:Right SEP

Fig. 4. Evoked potential values attained before the treatment and after the treatment. (a, b) BAEP $=$ brainstem auditory evoked potential, (c) VEP = visual evoked potential, (d, e) SEP = somatosensory evoked potential, (f, g) P200, P300 = visual event related evoked potential.. 
to the sub-dimensions of change in general health and in sexual functions in one year were compared, posttreatment values were found to be significantly lower (According to Wilcoxon rank-sum test: change in health; $p=0.005$, sexual function; $p=0.008$ ) (Table 4).

Mean right and left VEP values, mean right and left BAEP values, mean lower and upper SEP values, and mean p200 and p300 values of the patients obtained before the treatment and after the treatment were matched. When the evoked potential values were statistically compared based on the matched-paired ttest, no significant difference was observed (Fig. 4).

\section{DISCUSSION}

The relationship between the clinical type of MS, physical disability and depression of the patients, and fatigue has been discussed for many years. Neurological impairment and fatigue affect the quality of life of MS patients adversely, as does fatigue and depression, as demonstrated by results from the EDSS [10]. While some studies have shown there to be no relationship between age, gender, duration of disease and fatigue [11-13], others have reported that fatigue increases in parallel with age and longer duration of disease [14-16]. In the present study, no statistically significant relationship was detected between scores on the FSS and the frequency of seizures.

Depression is a symptom which usually accompanies MS, having a prevalence of above $50 \%$ $[17,18]$. Inconsistent results have been reported in studies examining the relationship between depression and fatigue. Several studies have revealed there to be a moderate [19, 20] or strong [21] relationship, whereas others have found there to be no relationship $[22,23]$. For example, in a study by Flachenecker et al. [24], which included 151 diseases, the FAS scores of the patients with depression were significantly higher than those of the patients without depression. Although depressive and anxious patients complained about fatigue more, only a weak linear correlation between fatigue and depression and anxiety was revealed [13]. As fatigue is regarded as a feature of depression, overlapping is to be expected. On the other hand, this point emphasizes the importance of defining fatigue clearly. In the present study, no statistically significant relationship was observed between the pretreatment scores obtained on the Beck's Depression Inventory and the FAS. Treatment of depression in MS may not lead to a reduction in the complaints about fatigue. Mohr et al. [25] reported a significant improvement only in global fatigue severity among the four sub-dimensions (global fatigue severity, situation-specific fatigue, results of fatigue, responsivity to rest and sleep) of the fatigue assessment instrument following a 16-week treatment with sertraline. The relationship between fatigue and depression remains unclear [26].

Studies have presented inconsistent results about the correlation between fatigue and EDSS as well. Several studies have determined there to be a positive correlation between these two variables [27, 28], some $[11,24,29]$ have found there to be a weak correlation $[30,31]$ and others have reported there to be no correlation $[32,33]$. The differences in the results found in these studies could have resulted from cohort features, the assessment tools used in fatigue measurement, change in neurobehavioral findings with medication, or differences in the designs applied by these studies [34]. In the present study, there was no statistically significant relationship found between fatigue and EDSS, the results of which could be attributed to the low number of patients in the study and the similar EDSS scores of the patients.

Fatigue is worse in progressive MS and worsens apparently when ambulation is affected. However, it should be noted that fatigue is a cause of morbidity, even among patients who do not complain about fatigue [13]. Studies have demonstrated that patients with progressive MS experience fatigue more frequently than patients with relapsing remitting MS $[15,35]$. In the present study, an evaluation of the relationship between clinical type of MS and fatigue could not be conducted due to the low number of patients and to the fact that a majority of the patients had relapsing remitting MS.

Fatigue is explicitly related to physical and psychological functional disruption. It has been found that fatigue rises dramatically when walking ability is affected [13]. Detection of high levels of physical fatigue plays a role in predicting an increase in disability in three years [36].

Analyses on quality of life sub-dimensions indicated that both fatigue and depression have a 
strong relationship with quality of life due to emotional problems and pain, and that depression has importance in predicting emotional well-being, cognitive function and health distress, regardless of the physical disability and fatigue levels of the patients [10]. Merkelbach et al. [37] argue that psychological symptoms are more important than physical disability with respect to fatigue.

Modafinil, amantadine, 4 aminopyridine, antidepressants, and L-carnitine are used for the treatment of MS-related fatigue . In the present study, comparison of the mean total Beck's Depression Inventory and FAS scores of the patients obtained after a 6-week modafinil treatment for overcoming their complaints about fatigue to their initial scores showed that the former were statistically significantly lower. These results implicitly indicate that the treatment of the fatigue symptoms seen in the patients reduced their depressive symptoms as well. The post-treatment values on the four sub-dimensions (physical health, cognitive health, change in health, sexual function) of the MSOoL- 54 were significantly lower than the pretreatment values of these dimensions, thereby supporting that modafinil treatment was useful for the patients. This outcome suggests that fatigue symptom affects the quality of life of MS patients adversely, and that the treatment of fatigue symptom improves their quality of life. Rammohan et al. compared the scores attained on fatigue scales after placebo with the scores found after a 2-week modafinil treatment administered as $200 \mathrm{mg}$ /day and reported there to be an apparent improvement in fatigue symptom following modafinil treatment [38]. A double blind study that comparatively analyzed the use of placebo and modafinil for 8 weeks among MS patients with fatigue determined that administration of modafinil improved not only fatigue symptoms but also attention and manual skill performances [39].

To the best of the present researchers' knowledge, there is no study examining the effect that modafinil treatment for MS-related fatigue has on evoked potentials in MS patients, where the aim is to measure the treatment results quantitatively. The closest study found, in terms of similarity to the present one, was the one conducted by Sangal et al., where a visual P300 evoked potential procedure was implemented to detect the response of narcolepsy patients to modafinil treatment; it was reported that such neurophysiological tests are not effective for detecting the response to modafinil treatment earlier [38]. In the analysis conducted in the present study, where BEAP, SEP, VEP, and visual P300 evoked potential methods were used before and after the modafinil treatment of the patients, it was observed that the well-being of the patients after the treatment, which was determined with subjective methods, did not affect the neurophysiological tests.

According to a study which evaluated visual and brainstem auditory-evoked potentials of MS patients on the basis of the presence and severity of fatigue, P100 latency (interocular latency difference) increased significantly when the patients with high fatigue severity were compared to MS patients without fatigue symptom [40]. The same study revealed BAEP anomalies (prolonged interlatency between BAEP 13-5 components) among MS patients with moderate and severe fatigue. This result indicates that there are conduction disturbances inside the brain stem, which suggests that the progression rate and disability of these sub-groups are extremely high.

\section{CONCLUSION}

Fatigue is a very frequently-seen symptom in MS patients and affects their quality of life. When modafinil, whose use in narcolepsy treatment was approved by the FDA, was administered to the MS patients, it was observed that their fatigue symptoms declined and their quality of life improved as compared to the pre-treatment period. However, the modafinil treatment had no effect on evoked potential procedures when it was applied to treat MS-related fatigue symptoms. Further studies involving more patient groups are required to determine the effect of evoked potential parameters on fatigue symptoms of MS patients and to detect the importance of certain parameters, like electrophysiological reagents.

\section{Conflict of interest}

The authors disclosed no conflict of interest during the preparation or publication of this manuscript.

\section{Financing}

The authors disclosed that they did not receive any grant during conduction or writing of this study. 


\section{Acknowledgment \\ We thank Fulya Çelikel, the health technician, for his contribution to the neurophysiology laboratory.}

\section{REFERENCES}

[1] Ozakbas S, Cagiran I, Ormeci B, Idiman E. Correlations between multiple sclerosis functional composite, expanded disability status scale and health-related quality of life durin and after treatment of relapses in patients with multiple sclerosis. $\mathrm{J}$ Neurol Sci 2004;218:3-7.

[2] Kurtzke JF. Rating neurological impairment in multiple sclerosis: an Expanded Disability Status Scale (EDSS). Neurology 1983;33:1444-52.

[3] Freal JE, Kraft GH, Coryell JK. Symptomatic fatigue in multiple sclerosis. Arch Phys Med Rehabil 1984;65:135-8.

[4] Krupp LB. Fatigue in Multiple Sclerosis A Guide to Diagnosis and Management, Demos Medical Publishing Inc 2004.

[5] Michielsen HJ, De Vries J, Van Heck GL. Psychometric qualities of a brief self-ratedfatigue measure: The Fatigue Assessment Scale (FAS). J Psychosom Res 2003;54:345-52.

[6] Mathiowetz V. Test-retest reliability and convergent validity of the Fatigue Impact Scale for persons with multiple sclerosis. Am J Occup Ther 2003;57:389-95.

[7] Vicrey BG, Hays RD, Harooni R, Myers LW, Ellison GW. A health-related quality of life measure for multiple sclerosis. Qual Life Res 1995;4:187-206.

[8] Türkdoğan D. Olaya İlişkin Endojen Potansiyeller. Akyüz G. (Ed): Elektrodiagnoz. Bölüm:24. Ankara, 2003: pp. 411-21.

[9] Beck AT, Ward CH, Mendelson M, Mock J, Erbaugh J. An inventory for measuring depression. Arch Gen Psychiatry 1961;4:561-71.

[10] Kargarfard M, Eetemadifar M, Mehrabi M, Maghzi AH, Hayatbakhsh MR. Fatigue, depression, and health-related quality of life in patients with multiple sclerosis in Isfahan, Iran. Eur J Neurol 2012;19:431-7.

[11] Pellicano C, Gallo A, Li X, Ikonomidou VN, Evangelou IE, Ohayon JM, et al. Relationship of cortical atrophy to fatigue inpatients with multiple sclerosis. Arch Neurol 2010;67:447-53. [12] Tedeschi G, Dinacci D, Lavorgna L, Prinster A, Savettieri G, Quattrone A, et al. Correlation between fatigue and brainatrophy and lesion load in multiple sclerosis patients independent of disability. J Neurol Sci 2007;263:15-9.

[13] Mills R J, Young CA. The relationship between fatigue and other clinical features of multiple sclerosis. Mult Scler 2011;17:604-12.

[14] Schreurs KM, de Ridder DT and Bensing JM. Fatigue in multiple sclerosis: reciprocal relationships with physical disabilities and depression. J Psychosom Res 2002;53:775-81.

[15] Lerdal A, Celius EG, Moum T. Fatigue and its association with sociodemographic variables among multiple sclerosis patients. Mult Scler 2003;9:509-14.

[16] Tedeschi G, Dinacci D, Lavorgna L, Prinster A, Savettieri $\mathrm{G}$, Quattrone A, et al. Correlation between fatigue and brain atrophy and lesion load in multiple sclerosis patients independent of disability. J Neurol Sci 2007;263:15-9.

[17] Figved N, Klevan G, Myhr KM, Glad S, Nyland H, Larsen JP, et al. Neuropsychiatric symptoms in patients with multiple sclerosis. Acta Psychiatr Scand 2005;112:463-8.

[18] Scott TF, Allen D, Price TR, McConnell H, Lang D. Characterization of major depression symptoms in multiple sclerosis patients. J Neuropsychiatry Clin Neurosci 1996;8:31823.

[19] Schreurs KM, de Ridder DT, Bensing JM. Fatigue in multiple sclerosis: reciprocal relationships with physical disabilities and depression. J Psychosom Res 2002;53:775-81.

[20] Bakshi R, Shaikh ZA, Miletich RS, Czarnecki D, Dmochowski J, Henschel K, et al. Fatigue in multiple sclerosis and its relationship to depression and neurologic disability. Mult Scler 2000;6:181-5.

[21] Koch M, Mostert J, Heerings M, Uyttenboogaart M, De Keyser J. Fatigue, depression and disability accumulation in multiple sclerosis: a cross-sectional study. Eur J Neurol 2009; $16: 348-52$

[22] Vercoulen JH, Hommes OR, Swanink CM, Jongen PJ, Fennis JF, Galama JM, et al. The measurement of fatigue in patients with multiple sclerosis. A multidimensional comparison with patients with chronic fatigue syndrome and healthy subjects. Arch Neurol 1996;53:642-9.

[23] Iriarte J, Carreno M, de Castro P. [Fatigue and functional system involvement in multiple sclerosis]. Neurologia 1996;11:210-5. [Article in Spanish]

[24] Flachenecker P, Kümpfel T, Kallmann B, Gottschalk M, Grauer O, Rieckmann P, et al. Fatigue in multiple sclerosis: a comparison of different rating scales and correlation to clinical parameters. Mult Scler 2002;8:523-6.

[25] Mohr DC, Hart SL and Goldberg A. Effects of treatment for depression on fatigue in multiple sclerosis. Psychosom Med 2003;65:542-7.

[26] Daly E, Komaroff AL, Bloomingdale K, Wilson S, Albert MS. Neuropsychological function in patients with chronic fatigue syndrome, multiple sclerosis, and depression. Appl Neuropsychol 2001;8:12-22.

[27] Moller A, Wiedemann G, Rohde U, Backmund H, Sonntag A. Correlates of cognitive impairment and depressive mood disorder in multiple sclerosis. Acta Neurol Scand 1994;89:11721.

[28] Türkbay T, Yıldırım Y, Özakbaş S, Uzunel F. Multiple Sklerozlu Hastalarda Yorgunluk ve Yorgunluğun Etkisinin Değerlendirilmesi. Türk Nöroloji Dergisi 2004;10:515-20.

[29] van der Werf SP, Jongen PJ, Lycklama à Nijeholt GJ, Barkhof F, Hommes OR, Bleijenberg G. Fatigue in multiple sclerosis: interrelations between fatigue complaints, cerebral MRI abnormalities andneurological disability. J Neurol Sci 1998;160:164-70.

[30] Pittion-Vouyovitch S, Debouverie M, Guillemin F, Vandenberghe N, Anxionnat R, Vespignani H. Fatigue in multiplesclerosis is related to disability, depression and quality of life. J Neurol Sci 2006;243:39-45.

[31] Yaldizli Ö, Glassl S, Sturm D, Papadopoulou A, Gass A, Tettenborn B, et al. Fatigue and progression of corpus callosumatrophy in multiple sclerosis. J Neurol 2011;258:2199- 


\section{5.}

[32] Shaygannejad V, Janghorbani M, Ashtari F, Zakeri H. Comparison of the effect of aspirin and amantadine for thetreatment of fatigue in multiple sclerosis: a randomized,blinded, crossover study. Neurol Res 2012;34:854-8.

[33] Cruz Gómez ÁJ, Ventura Campos N, Belenguer A, Ávila C, Forn C. Regional brain atrophy and functional connectivitychanges related to fatigue in multiple sclerosis. PloS One 2013;8:e77914.

[34] Ayache SS, Chalah MA. Fatigue in multiple sclerosis -insights into evaluation and management. Neurophysiol Clin 2017;47:139-71.

[35] Johansson S, Ytterberg C, Hillert J, Widen Holmqvist L, von Koch L. A longitudinal study of variations in and predictors of fatigue in multiple sclerosis. J Neurol Neurosurg Psychiatry 2008;79:454-7.

[36] Debouverie M, Pittion-Vouyovitch S, Brissart H, Guillemin
F. Physical dimension of fatigue correlated with disability change over time in patients with multiple sclerosis. J Neurol 2008;255:633-6.

[37] Merkelbach S, Konig J, Sittinger H. Personality traits in multiple sclerosis (MS) patients with and without fatigue experience. Acta Neurol Scand 2003;107:195-201.

[38] Rammohan KW, Rosenberg JH, Lynn DJ, Blumenfeld AM, Pollak CP, Nagaraja HN. Efficacy and safety of modafinil (Provigil $($ ) ) for the treatment of fatigue in multiple sclerosis: a two centre phase 2 study. J Neurol Neurosurg Psychiatry 2002;72:179-83.

[39] Lange R, Volkmer M, Heesen C, Liepert J. Modafinil effects in multiple sclerosis patients with fatigue. J Neurol 2009;256:645-50.

[40] Sangal B, Sangal M, Belisle C. Visual P300 latency predicts treatment response to modafinil in patients with narcolepsy. Clin Neurophysiol 1999;110:1041-7. 